\title{
Educação financeira nos livros didáticos de Matemática do Ensino Médio
} Financial education in high school mathematics textbooks

\author{
David Pires Dias ${ }^{1}$ \\ Artur Alberti Gaban ${ }^{2}$
}

Resumo:O livro didático é uma importante ferramenta de auxílio ao professor, em particular, o de matemática para o professor de matemática. Este trabalho analisa como a Educação Financeira aparece nos livros didáticos de Matemática do Ensino Médio à luz dos ambientes de aprendizagem sugeridos por Ole Skovsmose em seus trabalhos de Educação Matemática Crítica. Percebe-se, nas atividades que tratam de Educação Financeira dessas coleções, a falta de equilíbrio entre os ambientes de aprendizagem e também o fato de existirem atividades que, em sua grande maioria, não possuem potencial e/ou contextualização que favoreçam o entendimento ou que coloquem o aluno em uma posição de investigador. Destacam-se dados levantados sobre as atividades desses livros e exemplos de como é possível transformar uma atividade que sugere um ambiente de aprendizagem em outra que pode levar a um ambiente diferente cuja direção favoreça e estimule o desenvolvimento do senso crítico e da formação cidadã.

Palavras Chave: Educação Financeira, Ambientes de aprendizagem e Livro didático.

Abstract:The textbook is an important tool to help the teacher, in particular, the mathematics to the math teacher. This paper analyzes how the Financial Education appears in the textbooks of Mathematics of High School, based on the learning environments suggested by Ole Skovsmose in his work of Critical Mathematical Education. It can be seen in the activities that deal with Financial Education in these collections, the lack of balance between learning environments and also the fact that there are activities that in the great majority, don't have potential and / or contextualization that help the understanding or that place the student in a researcher position. We highlight data collected on the activities of these books and examples of how it is possible to transform an activity that suggests a learning environment in another that can lead to a different environment whose direction favors and stimulates the development of critical sense and citizen formation.

Key Words: Financial Education, Learning Environment and Textbook.

\section{Introdução}

A necessidade de aprendizado de conhecimentos e competências matemáticas para o desenvolvimento pessoal e social é inequívoca atualmente, assim como a importância de

\footnotetext{
${ }^{1}$ Doutor em Ciências/Matemática pelo IME - USP 2008. Professor no Instituto de Matemática e Estatística da Universidade de São Paulo - IME/USP. E-mail: dpdias@ime.usp.br

${ }^{2}$ Possui Mestrado Profissional em Ensino de Matemática E-mail: dpdias@ime.usp.br
}

Tangram - Revista de Educação Matemática, Dourados - MS - v.2 n. 1, pp. 67 - 78 (2018) 


\section{Educação financeira nos livros didáticos de matemática do Ensino Médio}

saber lidar com problemas comuns a qualquer cidadão como: rendimentos, juros, despesas, salário, investimento, ética, sustentabilidade, dentre outros termos comuns à Educação Financeira. Ser educado financeiramente, ajuda o indivíduo na tomada de decisões e em planejamentos utilizando muitas vezes a Matemática para esse fim.

Um importante ambiente em que o aprendizado ocorre é o escolar e uma das ferramentas disponíveis para isto são os livros didáticos.

Didático, então, é o livro que vai ser utilizado em aulas e cursos, que provavelmente foi escrito, editado, vendido e comprado, tendo em vista essa utilização escolar e sistemática. Sua importância aumenta ainda mais em países como o Brasil, onde uma precaríssima situação educacional faz com que ele acabe determinando conteúdos e condicionando estratégias de ensino, marcando, pois, de forma decisiva, o que se ensina e como se ensina o que se ensina. (Lajolo, 1996, p. 4)

A relevância dos livros didáticos é tamanha que o Ministério da Educação, possui o Programa Nacional do Livro Didático (PNLD), programa bilionário que avalia, compra e distribui os livros que poderão ser utilizados na rede pública da Educação Básica de todo o país.

Baseados na importância do livro didático no sistema de educação brasileiro, na magnitude que tomou o PNLD e na necessidade de oferecer Educação Financeira aos estudantes da Educação Básica, este texto propõe uma análise de atividades que envolvem Educação Financeira, presentes nos livros didáticos voltados ao Ensino Médio e aprovados pelo PNLD referente ao ano de 2015. Tal análise é feita a luz dos ambientes de aprendizagem sugeridos pela teoria sobre cenários para investigação, introduzidos por Skovsmose (2000).

\section{Cenários de Investigação}

O contraponto entre a matemática do cotidiano e a escolar é um tema bastante estudado. De Freudenthal com a Educação Matemática Realística, na década de setenta, passando por D’Ambrósio, na década seguinte, com a Etnomatemática até Skovsmose (2000) com a Educação Matemática Crítica. Dentre outros assuntos, é destacada a importância de propiciar ambientes reais de ensino que produzam significado para o aluno em particular. Segundo Skovsmose, para pensar em educação crítica, com o

Tangram - Revista de Educação Matemática, Dourados - MS - v.2 n. 1, pp. 67-78 (2018) 


\section{Educação financeira nos livros didáticos de matemática do Ensino Médio}

desenvolvimento da materacia ${ }^{3}$, é necessário que se considere o currículo, observando aspectos como aplicabilidade dos temas, interesses subjacentes, pressupostos, além das funções e limitações do tema em si. Além disso, também é fundamental uma intensa interação entre aluno e professor.

[...] os estudantes, embora suas experiências sejam falhas, fragmentárias, etc., também têm uma experiência geral, que no diálogo com o professor, permite-lhes identificar assuntos relevantes para o processo educacional [...] se uma educação pretende desenvolver uma competência crítica, tal competência não pode ser imposta aos estudantes, deve, sim, ser desenvolvida com base na capacidade existente. (Skovsmose, 2013, p. 18)

Skovsmose (2000) define Cenários para Investigação como um ambiente que pode dar suporte a um trabalho de investigação, que convida os alunos a interagir, formulando perguntas e buscando respostas e explicações. Tais cenários caracterizam-se pela aceitação dos envolvidos e dependem substancialmente da natureza do problema (atratividade), do professor (agente responsável por estimular as discussões) e dos alunos (participação ativa no cenário proposto). Suportado por essas ideias Skovsmose classifica três tipos de ambientes de aprendizagem matemática: ambientes exclusivos da e para a matemática (exercícios envolvendo matemática sem preocupação com qualquer contextualização), ambientes de semirrealidade (problemas contextualizados para dar um sentido à proposta, com pretextos e sem preocupação com veracidade e viabilidade) e ambientes reais (atividades ou cenários reais com propostas cotidianas verídicas).

Para cada um dos ambientes de aprendizagem, sugeridos por Skovsmose (2000), existem dois tipos diferentes de abordagem, exercícios e cenário para investigação, conforme Quadro 1 a seguir. Cada um dos ambientes de aprendizagem pode ser abordado das duas maneiras, dependendo de como é apresentado.

Quadro 1 - Ambientes de Aprendizagem

\begin{tabular}{|c|c|c|}
\hline & Exercícios & Cenário para Investigação \\
\hline Referência à Matemática Pura & $(1)$ & $(2)$ \\
\hline Referência à Semirrealidade & $(3)$ & $(4)$ \\
\hline Referência à Realidade & $(5)$ & (6) \\
\hline
\end{tabular}

3 "Materacia não se refere apenas às habilidades matemáticas, mas também à competência de interpretar e agir numa situação social e política estruturada pela matemática” (Skovsmose, 2000, p. 2).

Tangram - Revista de Educação Matemática, Dourados - MS - v.2 n. 1, pp. 67-78 (2018) 


\section{Educação financeira nos livros didáticos de matemática do Ensino Médio}

Fonte: Skovsmose (2000, p. 8), reformatado pelos autores.

O item (1), é o exercício que tem apenas a finalidade matemática, que visa a prática de conceitos com enunciados que envolvem, em geral, termos como resolva, calcule, efetue, etc. O item (2) também se refere a algo que se preocupa apenas com a matemática como produto final, mas sua abordagem deve levar o aluno a investigar fatos para concluir algo, mesmo que de utilidade puramente matemática, como por exemplo, atividades que envolvam argumentação, validação através de justificativas, alternativas de resolução ou de enunciado, dentre outras.

No que se refere ao ambiente de semirrealidade, o item (3) remete a exercícios que trazem elementos da realidade com o intuito de contextualizar a situação, mas sem considerar a coerência do enunciado com a realidade de fato, por exemplo:

Um feirante A vende maçãs a $0,85 € \mathrm{o} \mathrm{kg}$. Por sua vez, o feirante $\mathrm{B}$ vende $1,2 \mathrm{~kg}$ por $1,00 €$. (a) Que feirante vende mais barato? (b) Qual é a diferença entre os preços cobrados pelos dois feirantes por $15 \mathrm{~kg}$ de maçãs?Certamente, fala-se de maçãs, compras e preços. Mas não acredito que a pessoa que construiu esse exercício tenha feito alguma investigação empírica sobre a maneira como as maçãs são vendidas ou tenha entrevistado alguém de modo a descobrir as circunstâncias em que seria relevante comprar $15 \mathrm{~kg}$ de maçãs. A situação é artificial. (Skovsmose, 2000, p.8)

Dentro da ideia do que é tratado como semirrealidade, o item (4) é utilizado como recurso para que o aluno explore, evidencie, questione, relacione, analise e formule suas hipóteses e ideias.

Vale destacar que para Skovsmose, assim como para Santos (2010), um dos problemas em trabalhar com a semirrealidade, pretexto para Santos, é o fato da incoerência, muitas vezes sutil e outras nem tanto, de alguns dados com a própria realidade poder agravar o desinteresse pela atividade.

Quanto à realidade, o item (5) trata de exercícios que estão presentes no cotidiano das pessoas, exercícios envolvendo aspectos reais, já no (6) busca-se vivenciar a realidade e não somente cópia dela rascunhada dentro de uma sala de aula, objetiva-se que os alunos questionem, participem e se empenhem em um projeto real com variáveis e problemas reais, não para criar uma realidade, mas para vivê-la de fato.

Ambientes de aprendizagem envolvendo Educação Financeira Tangram - Revista de Educação Matemática, Dourados - MS - v.2 n. 1, pp. 67-78 (2018) 


\section{Educação financeira nos livros didáticos de matemática do Ensino Médio}

A análise, dos ambientes de aprendizagem que tratam de Educação Financeira nos livros didáticos de Ensino Médio aprovados no PNLD 2015, se divide em dois focos. O primeiro observa a porcentagem de atividades sobre esse tema em relação a todas as outras atividades de uma dada coleção, verificando-se também a distribuição dessas atividades ao longo dos capítulos. O segundo foco considera a distribuição dos ambientes envolvendo Educação Financeira em relação a classificação de ambientes de aprendizagem apresentada na seção anterior.

Em sua dissertação, Gaban (2017) apresenta uma análise detalhada das obras de Matemática aprovadas pelo PNLD 2015, voltado a livros do Ensino Médio, verificando a distribuição das atividades, envolvendo Educação Financeira, em relação a todas as atividades pertinentes ao livro. Esse texto traz tabelas com a contagem da quantidade de exercícios que tratam de Educação Financeira e do total de exercícios de cada capítulo de cada livro de todas as coleções, e também a porcentagem de atividades, que envolvem Educação Financeira, em relação ao total de atividades, além de gráficos ilustrativos e comparativos sobre esses valores.

Dois aspectos devem ser destacados na análise dos números apresentados por Gaban (2017), o primeiro diz respeito ao fato de existirem coleções que distribuem as atividades de Educação Financeira ao longo dos diversos capítulos da obra, enquanto outras apresentam capítulos inteiros sem nenhuma atividade voltada a esse tema.

\footnotetext{
Um fato interessante a se ressaltar é que quatro das seis coleções apresenta um formato bastante parecido, no que diz respeito a aparição e distribuição de atividades relativas a Educação Financeira. Todas as quatro têm, no total, por volta de $4,5 \%$ de atividades sobre o assunto e também apresentam inúmeros capítulos sem nenhum exercício tratando do tema em questão. Fazer da Educação Financeira um assunto transdisciplinar ainda é uma tarefa pouco explorada nos livros didáticos, uma vez que nem mesmo dentro dos conteúdos da própria Matemática tal distribuição é feita, talvez por um desconhecimento dos professores sobre o assunto, mas vemos que isso é possível, como tenta fazer a coleção Matemática - Ensino Médio. (Gaban, 2017, p. 42)
}

Outro aspecto é a concentração de atividades envolvendo Educação Financeira em capítulos específicos e destinados ao tema. Pois a comparação, quando na maioria das coleções são eliminados da contagem realizada os capítulos específicos sobre Matemática Financeira, reduz as atividades a aproximadamente metade do total verificado anteriormente,

Tangram - Revista de Educação Matemática, Dourados - MS - v.2 n. 1, pp. 67-78 (2018) 


\section{Educação financeira nos livros didáticos de matemática do Ensino Médio}

isto é, quando são consideradas apenas as atividades sobre Educação Financeira que estão em capítulos sobre temas diversos, estas representam aproximadamente 50\% do total de atividades da coleção sobre o assunto, como destacado em "Ao retirarmos os capítulos sobre Matemática Financeira, a porcentagem de exercícios nas coleções em geral, caiu pela metade, isso significa que esse tipo de exercícios está mais concentrado nos capítulos específicos[...]”. (Gaban, 2017, p. 44)

No que se refere ao segundo foco da análise, observando especificamente a distribuição das atividades envolvendo Educação Financeira segundo a classificação dos ambientes de aprendizagem, percebe-se uma maior concentração em ambientes do tipo (1), (2) e (3), inclusive com coleções que não apresentam ambientes dos tipos (5) e (6), como alertam Dias e Gaban

[...] em sua maioria, as atividades propostas nas coleções são exercícios que oferecem ambientes do tipo (1), (2) e (3), algumas, por exemplo, não apresentam nenhuma atividade classificada como dos tipos (5) ou (6), o que não é o desejado. Por isso, se torna parte importante do projeto, analisar as potencialidades das atividades propostas e oportunamente sugerir como tais problemas podem ser transformados em ambientes de aprendizagem mais interessantes e propícios a despertar no aluno uma vivência da realidade matemática desenvolvendo sua criticidade e consequentemente suas habilidades sociais. (Dias; Gaban, 2016, p. 11)

Além disso, a concentração em Ambientes dos tipos (1), (2) e (3) também é desigual, pois grande parte das atividades pode ser classificada como de apenas um desses ambientes, a saber o (3).

\footnotetext{
Em sua grande maioria, as atividades encontradas nas coleções são classificadas como do tipo (3), em que, por fazerem referência à Matemática Financeira utilizando-a por meio de diversos conceitos da matemática, como função, progressão, dentre outros, caracterizam ambientes que são exercícios referentes à semirrealidade, apesar de muitas vezes terem contextualizações tão irrelevantes que poderiam ser classificados como um ambiente do tipo (1) [...]. (Dias; Gaban, 2016, p. 7)
}

Os fatos anteriores corroboram com a ideia de que a distribuição das atividades envolvendo Educação Financeira na maioria das obras aprovadas pelo PNLD 2015 está concentrada em capítulos específicos destinados a Matemática Financeira e, além disso, tais atividades não são variadas quando considerados os ambientes de aprendizagem sugeridos por Skovsmose (2000).

Tangram - Revista de Educação Matemática, Dourados - MS - v.2 n. 1, pp. 67-78 (2018) 


\section{Educação financeira nos livros didáticos de matemática do Ensino Médio}

\section{Sugestões e análise de algumas atividades}

A fim de exemplificar como atividades classificadas de acordo com um tipo de ambiente de aprendizagem podem ser modificadas de modo a permitir uma nova caracterização quanto ao seu ambiente, apresenta-se a seguir, a atividade que aparece na página 209 do primeiro livro da coleção intitulada Matemática Ciência e Aplicações, dos autores Gelson Iezzi, Osvaldo Dolce, David Degenszajn, Roberto Périgo e Nilze de Almeida, destinada ao primeiro ano do Ensino Médio.

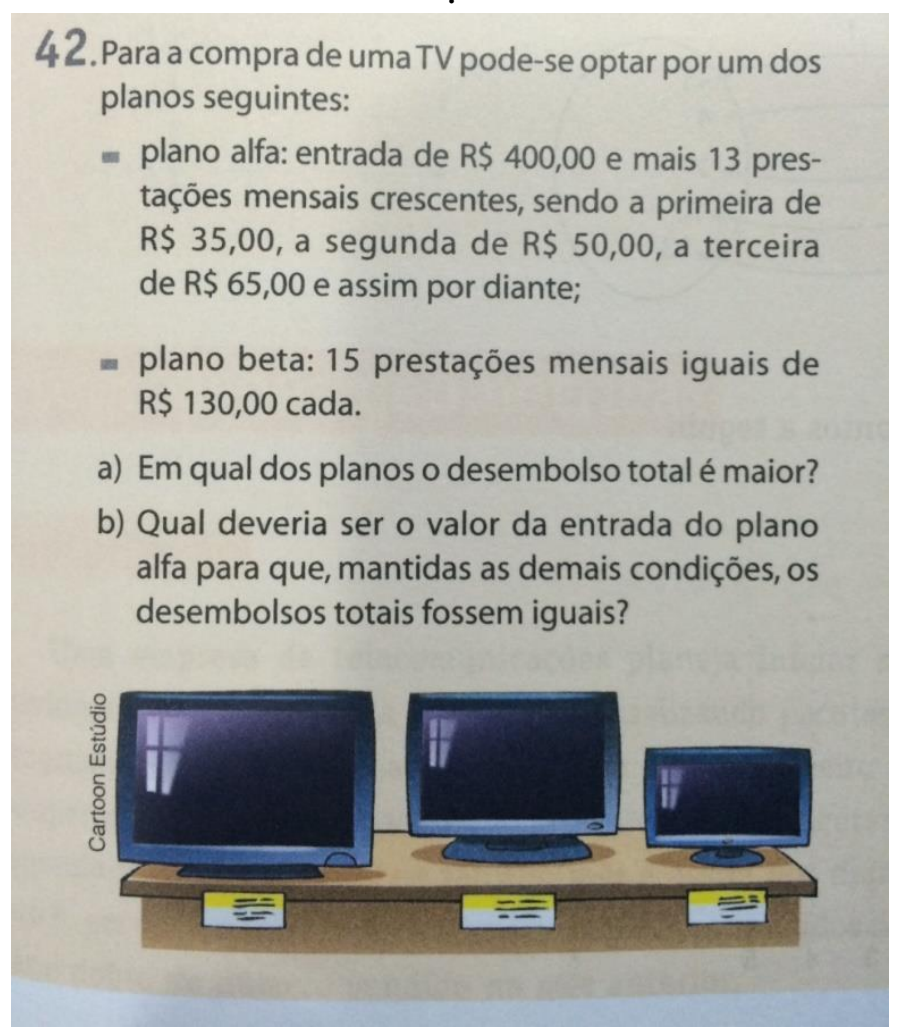

Figura 1 - Atividade sobre soma de P.A

Fonte: Iezzi et al. (2013a, p. 209).

O enunciado deste exercício está na seção que trata de Progressões denominada Soma dos n primeiros termos de uma P.A, e foi classificado como um ambiente de aprendizagem do tipo (3), pois trata do financiamento de um televisor ${ }^{4}$.

4 Cabe destacar que, apesar de classificado com Ambiente do tipo (3), não seria difícil e nem estranho caracterizá-lo como do tipo (1), já que o exercício trata exclusivamente da soma de P.A. e a Matemática Financeira é um pretexto para se chegar ao assunto, sem a preocupação da relação natural ou realística entre conceito e contexto.

Tangram - Revista de Educação Matemática, Dourados - MS - v.2 n. 1, pp. 67-78 (2018) 


\section{Educação financeira nos livros didáticos de matemática do Ensino Médio}

A análise do enunciado pode suscitar algumas perguntas como: "Existe cotidianamente um parcelamento como esse?", "Há presença de juros nessa compra? Ela é evidente?", "Não existe a possibilidade de pagamento à vista?". Dúvidas como essas podem surgir dentro e fora da sala de aula, durante uma simples leitura do exercício, independente de quem seja o leitor. Ao se considerar possíveis questionamentos no enunciado da atividade ou em sugestões destinadas ao professor, num eventual livro ou manual destinado a este, poderiam ser dirimidas dúvidas dos alunos e professores em relação à atividade, assim como torná-la passível de uma nova classificação segundo o ambiente de aprendizagem em que se enquadra, por exemplo, transformar-se uma atividade do tipo (3), em algo do tipo (5) que mesmo sendo um exercício passa a ser considerado um Cenário para Investigação.

A transformação em Cenário para Investigação passa por fatos como o do professor propor aos alunos que determinem o preço real de um aparelho de TV e pesquisem diferentes formas de parcelamento de um televisor, com o objetivo de dar um caráter real ao assunto, trazendo a natural relação entre a Progressão Aritmética e os juros de um parcelamento, abrindo espaço para discussões e mais indagações sobre a atividade e o tema como um todo.

Outro exemplo que merece destaque, por ser um dos poucos a estar presente num capítulo destinado a Geometria, encontra-se na obra intitulada Matemática - Ensino Médio, das autoras Katia Cristina Stocco Smole e Maria Ignez de Souza Vieira Diniz, presente na página 215 do segundo livro da coleção, destinado ao segundo ano do Ensino Médio.

Tangram - Revista de Educação Matemática, Dourados - MS - v.2 n. 1, pp. 67-78 (2018) 


\section{Educação financeira nos livros didáticos de matemática do Ensino Médio}

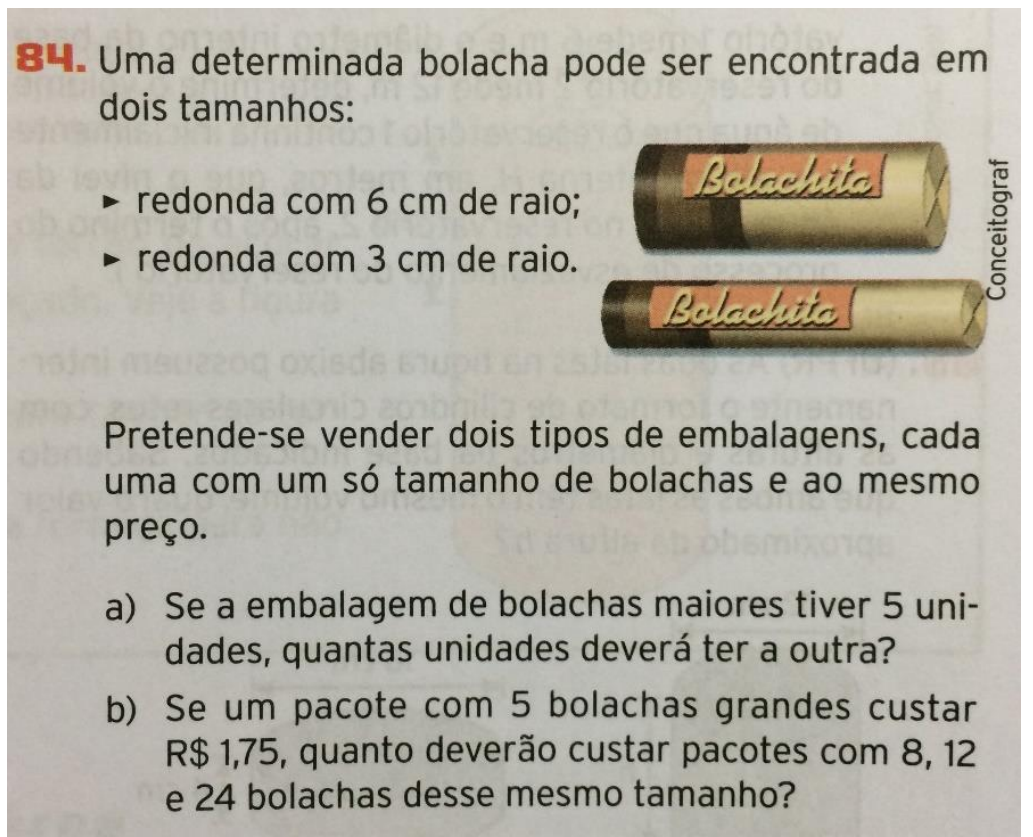

Figura 2 - Atividade envolvendo Educação Financeira e Geometria

Fonte: Smole e Diniz (2013b, p. 215).

O exemplo apresentado está inserido no capítulo intitulado Geometria Métrica Espacial, na seção denominada Área da superfície e volume dos corpos redondos e pode ser classificado como um Ambiente de Aprendizagem do tipo (3). Mas, assim como o exemplo anterior, o escopo financeiro da atividade é apenas um pretexto para se atingir o objetivo do exercício, que no caso do item a é determinar a quantidade de bolachas que deve ter uma das embalagens e no item $b$ trabalhar com proporcionalidade.

Observe que a pergunta do item a pode gerar confusão, uma vez que o exercício diz que ambos os pacotes deverão ter o mesmo preço, porém não faz menção alguma ao valor de nenhum dos dois pacotes, e não existe uma comparação possível a menos que seja interpretado que ambos os pacotes têm que ter o mesmo valor para a massa ou o volume, assim, ao diminuir o raio da circunferência da bolacha faz sentido termos bolachas de raio menor num pacote de maior comprimento. Sem informações adicionais como essas o item dá margem a interpretações distintas.

Já o item b, que traz explicitamente conceitos monetários, trata basicamente de proporcionalidade, visto que o preço de cinco bolachas foi estabelecido com o objetivo de se encontrar o valor dos demais pacotes que possuem 8, 12 e 24 bolachas, o que pode ser feito, por exemplo, determinando o valor de uma bolacha e multiplicando tal valor pela quantidade de bolachas de cada um dos outros pacotes.

Tangram - Revista de Educação Matemática, Dourados - MS - v.2 n. 1, pp. 67-78 (2018) 


\section{Educação financeira nos livros didáticos de matemática do Ensino Médio}

Estratégias alternativas poderiam ser traçadas no exemplo anterior, demonstrando assim seu enorme potencial para explorar Geometria e a Educação Financeira ao mesmo tempo. Existe a possibilidade de, por exemplo, pedir aos estudantes que verifiquem no comércio a existência de pacotes de bolacha do mesmo tipo, mas em embalagens diferentes a fim de determinar o valor das embalagens, a quantidade de bolachas presente em cada uma delas e talvez o preço unitário de cada bolacha para uma possível verificação de qual dos pacotes apresenta melhor custo benefício, etc. Cabe observar que para a resolução de problemas como esse, o aluno precisará pensar em diferentes estratégias e uma delas pode envolver a ideia de trabalhar com massa, ou mesmo, com volume. Outra possível sugestão para modificar ou ampliar o exercício, seria pedir ao aluno que pensasse também no gasto com a embalagem, no seu impacto ambiental, etc. Abrindo assim, espaço para a discussão do motivo de existirem embalagens diferentes, qual seria a embalagem ideal segundo o ponto de vista do lucro do fabricante e qual seria em relação ao custo ambiental, etc.

As sugestões apresentadas são apenas uma pequena ilustração de como melhor explorar o potencial que alguns exercícios têm, isto porque atividades como essas abrem espaço para que sejam abordados assuntos como porcentagem, consumo, custo e meio ambiente, entre outros que corroboram e ajudam a consolidar a transversalidade da Educação Financeira.

\section{Considerações}

Skovsmose (2000) sustenta que a educação matemática deve mover-se entre os diferentes ambientes e que não considera a ideia de abandonar por completo os exercícios da educação matemática. Mais do que isso, os ambientes de aprendizagem não são classificados de forma a se preferir ou entender que um destes é melhor em relação ao outro, mas sim para que sejam levados em consideração em suas especificidades e igualdade de importância e relevância na formação do aluno, o que implica numa distribuição homogênea e ampla dos mesmo num livro didático e também ao longo do cotidiano escolar do estudante. Portanto, acredita-se que, ao contrário do observado anteriormente, os ambientes de aprendizagem deveriam existir em toda sua gama de opções e também estar bem distribuídos ao longo dos capítulos de cada livro e não concentrados em um ou dois tipos específicos em toda a coleção.

Tangram - Revista de Educação Matemática, Dourados - MS - v.2 n. 1, pp. 67-78 (2018) 


\section{Educação financeira nos livros didáticos de matemática do Ensino Médio}

Além disso, particularmente ao que se refere a Educação Financeira e sua transversalidade, a distribuição de atividades sobre esse tema é muito heterogênea ao longo das coleções, já que existem capítulos tratando especificamente do tema e diversos outros que não exploram o assunto. Quando unida a heterogeneidade da distribuição das atividades de Educação Financeira com a concentração em ambientes de aprendizagem específicos, existente nas coleções, desenha-se um cenário preocupante em relação ao contato que os estudantes de Ensino Médio terão com a Educação Financeira como um todo.

Por mais bem pensado e intencionado que seja o livro didático, não se pode delegar a ele todos os poderes, por isso levando em consideração a importância, por exemplo, da tríade professor-aluno-livro, são apresentados exemplos, específicos de Educação Financeira, de como uma atividade prevista pelo livro, pode ser transformada pelos agentes professor-alunos de forma a torná-la mais participativa e envolvente, modificando o aspecto de como a atividade pode ser abordada, incluindo aqui a passagem de um exercício para um Cenário de Investigação e de uma semirrealidade para a realidade, de forma a propiciar uma educação mais ampla, crítica e cidadã.

\section{Referências}

Brasil (2000) Secretaria de Educação Básica. Parâmetros Curriculares Nacionais (Ensino Médio). Brasília: MEC, 2000.

Brasil (2015) Fundo Nacional do Desenvolvimento da Educação. Guia do Livro Didático. Disponível em: <http://www.fnde.gov.br/programas/programas-do-livro/livrodidatico/guia-do-livro-didatico/item/5940-guia-pnld-2015> . Acesso em: 03 ago 2018.

Dias, D. P.; Gaban, A. A. (2016) Educação Financeira e o livro didático de Matemática: uma análise dos livros aprovados no PNLD 2015. Anais XII Encontro Nacional de Educação Matemática, São Paulo.

Gaban, A. A.(2016) Educação Financeira e o livro didático de Matemática: uma análise dos livros aprovados no PNLD. Dissertação (Mestrado) - Instituto de Matemática e Estatística, Universidade de São Paulo, São Paulo, 2016

Hofmann, R. M.; Moro, M. L. F. (2012) Educação matemática e educação financeira: perspectivas para a ENEF. Zetetiké, v. 20, n. 2, p. 37-54, jul./dez. 2012.

Iezzi, G. et al. (2013ª)Matemática: Ciência e Aplicações. 7 ed. São Paulo: Editora Saraiva, . v. 1 .

Iezzi, G. et al (2013b)Matemática: Ciência e Aplicações. 7 ed. São Paulo: Editora Saraiva, v. 2.

Tangram - Revista de Educação Matemática, Dourados - MS - v.2 n. 1, pp. 67-78 (2018) 


\section{Educação financeira nos livros didáticos de matemática do Ensino Médio}

Iezzi, G. et al (2013c)Matemática: Ciência e Aplicações. 7 ed. São Paulo: Editora Saraiva. v. 3.

Lajolo, M. (1996) Livro didático: um (quase) manual de usuário. Em aberto, Brasília, v. 16, n. 69, p. 3-9, jan./mar.

Santos, V. M.(2010) Eixos estruturadores do currículo de Ensino Médio e sua interpretação em textos didáticos de matemática. Anais do X Encontro Nacional de Educação Matemática, Salvador. Disponível em: <http://www.lematec.net.br/CDS/ENEM10/artigos/MR/MR23_Santos.pdf>. Acesso em: 03 de ago. 2018.

Skovsmose, O. (2000) Cenários para investigação. Bolema, Rio Claro, v. 13, n. 14, p. 66-91.

Skovsmose, O.(2013) Educação Matemática Crítica: A Questão da Democracia. 6 ed. Campinas: Papirus.

Smole, K. C. S.; Diniz, M. I. S V. (2013 $)$ Matemática - Ensino Médio. 8 ed. São Paulo: Editora Saraiva v. 1.

Smole, K. C. S.; Diniz, M. I. S V. (2013b)Matemática - Ensino Médio. 8 ed. São Paulo: Editora Saraiva, v. 2.

Smole, K. C. S.; Diniz, M. I. S V. (2013c) Matemática - Ensino Médio. 8 ed. São Paulo: Editora Saraiva, v. 3.

Enviado:26/09/2018

Aceito:10/11/2018

Tangram - Revista de Educação Matemática, Dourados - MS - v.2 n. 1, pp. 67-78 (2018) 